\title{
A REFORMA DO ENSINO MÉDIO: NOVOS DESAFIOS PARA A GESTÃO ESCOLAR
}

\section{LA REFORMA DE LA EDUCACIÓN SECUNDARIA: NUEVOS DESAFÍOS PARA LA GESTIÓN ESCOLAR}

\section{THE REFORM OF HIGH SCHOOL: NEW CHALENGES FOR SCHOOL MANAGEMENT}

\author{
Marcelo Siqueira Maia Vinagre MOCARZEL ${ }^{1}$ \\ Angelina Accetta ROJAS ${ }^{2}$ \\ Maria de Fátima Barros PIMENTA ${ }^{3}$
}

\begin{abstract}
RESUMO: A partir do diagnóstico do fracasso escolar, o Governo Federal propôs, por meio de uma Medida Provisória, um novo modelo de Ensino Médio, sob a justificativa de que se estaria respondendo à demanda da sociedade. Porém, o projeto traz mais desafios que soluções aos gestores escolares, na medida em que a operacionalização das propostas parece ser algo distante e também problemático. Este artigo busca discutir, a partir das alterações no texto legal e fazendo uso do ciclo de políticas como metodologia de pesquisa, quais os desafios que podem ser vislumbradas para os gestores de escolas públicas e privadas.
\end{abstract}

PALAVRAS-CHAVE: Ensino médio. Gestão. Carga horária.

RESUMEN: A partir del diagnóstico del fracaso de la educación, el Gobierno Federal propuso, por medio de una Medida Provisional, un nuevo modelo de Educación Secundaria, bajo la justificación de que se estaría respondiendo a la demanda de la sociedad. Sin embargo, el proyecto trae más desafíos que soluciones a los gestores escolares, en la medida en que la operacionalización de las propuestas parece ser algo distante y también problemático. Este artículo busca discutir, a partir de las alteraciones en el texto legal y haciendo uso del ciclo de políticas como metodología de investigación, cuáles son los desafios que pueden ser vislumbrados para los gestores de escuelas públicas y privadas.

PALABRAS CLAVE: Educación secundaria. Gestión. Carga horaria.

ABSTRACT: From the diagnosis of the failure of education, the Federal Government proposed, through a Provisional Measure, a new model of High School, under the

\footnotetext{
${ }^{1}$ Centro Universitário La Salle do Rio de Janeiro (Unilasalle-RJ), Niterói - RJ - Brasil. Professor do curso de Pedagogia. E-mail: marcelo.mocarzel@lasalle.org.br.

${ }^{2}$ Centro Universitário La Salle do Rio de Janeiro (Unilasalle-RJ), Niterói - RJ - Brasil. Professora do curso de Pedagogia. E-mail: angelina.rojas@lasalle.org.br.

${ }^{3}$ Centro Universitário La Salle do Rio de Janeiro (Unilasalle-RJ), Niterói - RJ - Brasil. Coordenadora e professora do curso de Pedagogia. E-mail: maria.pimenta@lasalle.org.br.
} 
justification that it would be responding to the demand of society. However, the project brings more challenges than solutions to school managers, since the operationalization of the proposals seems to be something distant and also problematic. This article seeks to discuss, from the changes in the legal text and making use of the policy cycle as a research methodology, what challenges can be envisaged for managers of public and private schools.

KEYWORDS: High school. Management. Workload.

\section{Introdução}

Em 23 de setembro de 2016 foi editada pelo Governo Federal a Medida Provisória n. 746/2016, que trazia importantes alterações à Lei de Diretrizes e Bases da Educação Nacional (BRASIL, 1996), propondo um novo desenho para o Ensino Médio. Em 8 de fevereiro de 2017, o texto da MP foi convertido em norma jurídica, após aprovação da Câmara dos Deputados e do Senado, trazendo algumas modificações em relação à proposta original do executivo. Mas, em grande medida, o teor das mudanças permaneceu inalterado, impondo aos gestores dos sistemas de ensino e aos gestores escolares novos desafios, alguns deles sem perspectiva próxima de superação. Este artigo busca, através da análise da norma em questão (BRASIL, 2017), expor as possíveis dificuldades que os gestores terão para materializar o "novo" Ensino Médio. Para isso, fazemos uso da abordagem do ciclo de políticas, inicialmente proposta por Ball e Bowe (1992), e depois ampliada por outros estudos (MAINARDES, 2006; BALL; MAINARDES, 2011; BALL, MAGUIRE; BRAUN, 2016).

A abordagem do ciclo de políticas leva em conta diferentes contextos e atores, pensando a política como um processo dinâmico, contínuo e repleto de influências, afastando-se de uma visão estatista, que teria no Estado seu único formulador. Parte-se então da ideia, teorizada pelos autores, de que a política educacional - ou a política pública em essência - faz parte de um ciclo. De acordo com Mainardes (2006, p. 49), os autores introduziram a "noção de um ciclo contínuo constituído por três facetas ou arenas políticas: a política proposta, a política de fato e a política em uso". Essas três visões possibilitam lançar mão de um prisma, que se aproxima do que Santos (2012) conceitua como "refração política": os desvios existentes entre a letra da lei e a norma em uso. A política proposta trata das intenções, não apenas dos governos e suas burocratas, mas de todos os atores envolvidos no debate, como sindicatos, entidades, escolas, grupos de pesquisa etc. Em seu desenrolar, a política se modifica, através de

RPGE - Revista on line de Política e Gestão Educacional, Araraquara, v. 22, n. esp.1, p. 159-176, mar., 2018. 
emendas, vetos, pedidos de vista, contestações públicas, decisões judiciais e outros mecanismos. A esse processo se dá o nome de política de fato, a partir da conceituação dos autores. Por fim, a "política em uso" é a vertente prática, que transforma a política a partir de interpretações sociais (BALL; BOWE, 1992).

Mainardes (2006) aponta que, logo em seguida, os autores refinaram sua proposição inicial, trazendo novos elementos à abordagem do ciclo de políticas. Afastando-se da ideia de implementação e formulação de políticas, como ações estáticas, os autores passaram a valorizar os processos e as arenas de disputa na construção da metodologia. Segundo eles, as políticas se constroem a partir de distintos contextos - contexto de influência, contexto da produção de textos, contexto da prática - sem um sentido linear ou evolucionista. Ao deixarem de lado a rigidez inicial, o ciclo de políticas passou a levar em conta aspectos linguísticos, diferenciando os tipos de textos das políticas. De um lado, tem-se o texto prescritivo (readerly), que limita a interação e a interferência do leitor; de outro, o texto editável (writerly), que "convida o leitor a ser coautor do texto" (MAINARDES, 2006, p. 50). Assim, em seu nascedouro, a política já carrega uma perspectiva de participação ou não.

Diante dessa abordagem, que tira do Estado - e do governo - a responsabilidade exclusiva de autoria das políticas públicas, entendemos que os atores sociais são de elevada importância para o seu desenrolar. Deve-se lembrar que política pública é algo diferente de lei: a política pública não necessita da lei para existir, há programas, por exemplo, que efetivam políticas públicas sem ordenamento legal qualquer; por outro lado, em uma lei, pode haver uma, várias ou nenhuma política pública. No caso da reforma do Ensino Médio, temos uma série de alterações na LDB e em outros dispositivos legais, que fomentarão, em nosso entender, distintas políticas públicas.

Enquanto Ball e Bowe (1992) adotam uma perspectiva metodológica sobre as políticas educacionais, Ozga (2000) as estuda sob um prisma epistemológico. A premissa do seu texto é que as políticas educacionais são objetos de interesse da comunidade educativa e que não devem representar ou estar a serviço exclusivo dos decisores políticos. Seu entendimento é de que a "[...] política é algo sobre o qual se discute, que não se oferece, em lápides de pedra, a populações que se mostram receptivas e gratas por isso [...]" (OZGA, 2000, p. 19). Segundo a autora, não há uma clara distinção entre o campo da política educacional e das políticas sociais, o que dificulta as investigações especializadas. Tampouco os professores, os maiores interessados nos resultados das investigações, se sentem parte de uma comunidade 
científica, o que impede o escrutínio das ações sobre a educação. De acordo com suas proposições, são as próprias pesquisas já realizadas que encorajam os profissionais da educação a realizarem novas, a esmiuçarem outros objetos e a desenvolverem pensamentos críticos e reflexivos face à política.

\title{
Políticas públicas educacionais em tempos de transição
}

A partir do processo de redemocratização do país, com o fim da Ditadura CivilMilitar (1964-1985) e a publicação da nova Constituição (1988), iniciou-se o debate sobre as novas diretrizes e bases da educação nacional. Naquele momento, a lei geral da educação vigente datava de 1961 e já tinha sido atravessada por normatizações ocorridas durante o regime de exceção, como as leis 5.540, de 1968 (reforma do sistema universitário) e 5.692, de 1971 (reforma do ensino básico).

De acordo com Saviani,

\begin{abstract}
Antes mesmo que os constituintes entrassem em ação, a IV Conferência Brasileira de Educação, realizada em Goiânia em agosto de 1986, teve como tema centra "A educação e a constituinte". E na assembleia de encerramento dessa Conferência foi aprovada a "Carata de Goiânia" contendo as propostas de educadores para o capítulo da Constituição referido à educação (SAVIANI, 2008, p. 35).
\end{abstract}

Portanto, confirma-se que a legislação sobre a educação já era pauta antes mesmo da formação da Assembleia Nacional Constituinte. Isso fez com que o primeiro projeto de uma nova LDB fosse apresentado ao Congresso ainda em 1988, por iniciativa do deputado Otávio Elísio (PMDB). As intensas disputas sobre o projeto de educação que se queria, entre forças conservadoras e progressistas, fez com que a lei só fosse aprovada, de fato, em 20 de dezembro de 1996, trazendo uma redação completamente diferente do projeto inicial e com a chancela autoral de Darcy Ribeiro.

Após aprovação da Constituição Federal de 1988, o Brasil pôde eleger seu primeiro Presidente por vias democráticas desde a eleição de Jânio Quadros, em 1960. Elegeu-se Fernando Collor de Melo, pertencente a uma família política tradicional de Alagoas, que trazia um discurso moralizador e, em certa medida, progressista. Mesmo tendo ficado pouco tempo no poder (1990 a 1992), após renunciar/sofrer impeachment a partir de graves denúncias de corrupção, Collor abriu as portas do Brasil para o capitalismo, algo que a Ditadura Civil-Militar não havia feito escancaradamente. O país

RPGE - Revista on line de Política e Gestão Educacional, Araraquara, v. 22, n. esp.1, p. 159-176, mar., 2018. 
começa a se comportar como país capitalista periférico e inicia-se um período de enxugamento do Estado e incentivo ao livre mercado. Vieira (2008) classifica como tempos de transição, uma vez que o país se transformava a partir do contexto global.

O vice-presidente de Collor, Itamar Franco, completa o seu mandato e torna-se pai do Plano Real, que buscou modernizar o sistema monetário nacional, até então vítima de uma aguda crise e de uma hiperinflação que atingia cifras astronômicas. O seu Ministro da Fazenda era o sociólogo Fernando Henrique Cardoso que, a partir do sucesso da nova moeda, se qualificou politicamente para ser o novo Presidente (19942002).

Do ponto de vista da orientação política e econômica, temos uma linha contínua que atravessa os três governos citados, ainda que com particularidades em cada um. No Governo Fernando Henrique Cardoso, as influências de organismos multilaterais como a Organização das Nações Unidas, o Banco Mundial e o Fundo Monetário Internacional passam a ser consideradas de alta relevância nas tomadas de decisão, da mesma maneira que já ocorria em países de capitalismo central ${ }^{4}$. Para Altmann (2002), as propostas do Banco Mundial foram as mais influentes no campo educacional brasileiro, na medida em que o organismo tem declarado, desde 1990, que seu principal objetivo é o combate à pobreza, tendo a oferta de ensino elementar como uma das suas principais recomendações. O próprio programa de governo de Fernando Henrique Cardoso trazia claramente vinculações com as prescrições do Banco Mundial. O ápice desse entrelaçamento entre o Brasil e Banco Mundial se dá em 1995, com Reforma Gerencial do Estado, comandada pelo então Ministro Luiz Carlos Bresser-Pereira. Neste ano foi implementado o "Plano Diretor da Reforma do Aparelho do Estado", conduzido pelo Ministério da Administração Pública e Reforma do Estado. Segundo o documento:

É preciso, agora, dar um salto adiante, no sentido de uma administração pública que chamaria de "gerencial", baseada em conceitos atuais de administração e eficiência, voltada para o controle dos resultados e descentralizada para poder chegar ao cidadão, que, numa sociedade democrática, é quem dá legitimidade às instituições e que, portanto, se torna "cliente privilegiado" dos serviços prestados pelo Estado. [...] É preciso reorganizar as estruturas da administração com ênfase na qualidade e na produtividade do serviço público; na verdadeira profissionalização do servidor, que passaria a perceber salários mais justos para todas as funções. Esta reorganização da

${ }^{4}$ Fazemos aqui uma distinção entre países de capitalismo central e países de capitalismo periférico, grupo que inclui os países em desenvolvimento, onde o capitalismo não é uma constante para toda a população, tais como o Brasil. 
máquina estatal tem sido adotada com êxito em muitos países desenvolvidos e em desenvolvimento (BRASIL, 1995, p. 7).

Na educação, recorre-se a quatro diferentes conjuntos de políticas públicas para exemplificar como esta perspectiva gerencialista do Estado influenciou - e ainda hoje influencia - a agenda nacional. São elas: as políticas de currículo, as políticas de avaliação, as políticas de valorização e as políticas de financiamento educacional. Há outras políticas que poderiam ser consideradas, mas essas quatro traduzem o que há mais latente na reconstituição da educação brasileira a partir de uma lógica de "quase mercado" (SOUZA; OLIVEIRA, 2003).

Uma das primeiras orientações do Banco Mundial cumpridas pelo Governo Fernando Henrique Cardoso (vale lembrar que o Ministro da Educação à época era Paulo Renato de Souza, técnico de carreira do Banco Mundial) foi a instituição de uma nova política curricular. Uma das prescrições do órgão aponta para a padronização do ensino no território nacional, a fim de poder gerar elementos de comparação. Por isso a centralidade de investimentos em livros-textos é uma importante recomendação para países que contraem empréstimos. No bojo dessas orientações, o Ministério da Educação convidou renomados consultores para elaborarem os Parâmetros Curriculares Nacionais (PCNs), que deveriam servir como orientações para as escolas definirem o que deveriam ensinar. Em 1997, foram publicados os primeiros PCNs, seguidos pelos Referenciais Curriculares para a Educação Infantil. Como aponta Luiz Antônio Cunha (1996), a LDB aprovada um ano antes tinha uma concepção minimalista e não se debruçava sobre aspectos cruciais da educação, como o debate sobre currículo ou avaliação. Sendo assim, novas políticas tiveram que ser formuladas para dar conta das fragilidades do texto legal, seguindo a receita de doses homeopáticas, como ironiza Saviani (2008).

A discussão a respeito dos PCNs foi intensa e culminou na reformulação das Diretrizes Curriculares Nacionais em todos os níveis, uma vez que o Conselho Nacional de Educação entendeu que os Parâmetros não deveriam ser obrigatórios. Hoje, esse debate se arrasta para a definição da Base Nacional Curricular Comum, que pode vir a engessar ainda mais o trabalho docente com vistas às avaliações em larga escala.

RPGE - Revista on line de Política e Gestão Educacional, Araraquara, v. 22, n. esp.1, p. 159-176, mar., 2018. 
Nas políticas de avaliação, o marco mais importante é a criação do Sistema de Avaliação da Educação Básica - SAEB - ainda em 1988, seguindo os moldes do PISA ${ }^{5}$. O SAEB surgiu como uma prova amostral e hoje constitui-se como um verdadeiro sistema avaliativo, agregando outros instrumentos como a Prova Brasil, a Avaliação Nacional da Alfabetização (ANA) e o Exame Nacional do Ensino Médio (Enem). A avaliação em larga escala, como apontam Souza e Oliveira (2003, p. 875), “torna-se peça central nos mecanismos de controle" e "legitima 'valorações' úteis à indução de procedimentos competitivos entre escolas e sistemas para melhorar pontuações nos rankings $[\ldots] "$.

Ressalta-se que as políticas avaliativas tomaram grande corpo e mesmo nos governos seguintes (Luiz Inácio Lula da Silva, 2003-2010 e Dilma Roussef, 20112016), com orientações político-ideológicos diferentes dos governos anteriores, houve investimento e aperfeiçoamento das estratégias avaliativas enquanto mecanismos de controle. Essas políticas trazem à tona a ideia de um Estado Avaliador, que possibilita a descentralização das práticas pedagógicas, mas, no final do processo, exige que todos passem pelos mesmos critérios em exames e testes unificados.

Os resultados das políticas avaliativas produzem o que convencionou-se chamar de efeitos de responsabilização ou accountability (BALL 2005; HYPOLITO, 2010). Trata-se de um sistema de prestação de contas, que direciona à escola, aos gestores e, principalmente, aos professores, a responsabilidade exclusiva pelo sucesso ou pelo fracasso dos alunos. Esse modelo, baseado na lógica do mérito, acaba por comprometer o trabalho docente, na medida em que os objetivos passam a ser os resultados e não a qualidade dos processos. Isso impacta nas políticas de valorização, que passaram a ter como medidas os resultados em testes em larga escala e índices impostos pelo governo.

Em 2007, já no Governo Lula, foi criado o Ideb - Índice de Desenvolvimento da Educação Básica - indicador calculado com base no fluxo dos estudantes e nos resultados dos mesmos em testes estandardizados. A partir da divulgação dos primeiros resultados, começou-se a colher os primeiros efeitos no que tange à meritocracia.

\footnotetext{
${ }^{5}$ O Programme for International Student Assessment (Pisa) - Programa Internacional de Avaliação de Estudantes - é uma iniciativa de avaliação comparada, aplicada de forma amostral a estudantes matriculados a partir do $8^{\circ}$ ano do ensino fundamental na faixa etária dos 15 anos, idade em que se pressupõe o término da escolaridade básica obrigatória na maioria dos países. O Pisa é coordenado pela Organização para Cooperação e Desenvolvimento Econômico (OCDE), havendo uma coordenação nacional em cada país participante. No Brasil, a coordenação do Pisa é responsabilidade do Inep. Disponível em: 〈http://portal.inep.gov.br/pisa〉. Acesso em: 21 dez. 2016.
} 
Diversos sistemas municipais e estaduais (inclusive a cidade do Rio de Janeiro) passaram a adotar políticas de remuneração variável (HYPOLITO, 2010), baseadas nos resultados do Ideb.

A lógica gerencialista da reforma do Estado atingiu seu ápice (ou pelo menos espera-se), na medida em que as escolas públicas passaram a se comportar de fato como empresas, com metas e bônus por cumprimento, ainda que, antes da instituição do índice, já se experimentasse no país um processo de flexibilização e precarização do trabalho docente (OLIVEIRA, 2004). A precarização do trabalho passa, sobretudo, pelas políticas de financiamento da educação. Por mais que tenham ocorrido iniciativas para reestruturar o financiamento da educação, como a criação do FUNDEF (Fundo de Manutenção e Desenvolvimento do Ensino Fundamental e de Valorização do Magistério) em 1996, não houve, de fato, uma grande injeção de recursos que pudessem transformar o cenário de precarização de escolas e salários até o Governo Dilma Roussef. Neste, foi aprovado o Plano Nacional de Educação (2014-2024), que estabelece, em sua meta 20, que até o final de sua vigência, $10 \%$ do Produto Interno Bruto brasileiro deve ser direcionado ao financiamento da educação. Hoje, políticas como a reforma do Ensino Médio e a Emenda Constitucional n. 95 se sobrepuseram ao Plano Nacional de Educação, na medida em que inverteram prioridades. Isso fez com que os gestores de escolas públicas e privadas ficassem sem rumo, aguardando decisões centrais que podem modificar a avaliação, o currículo, a remuneração e qualificação dos profissionais e o próprio financiamento das escolas.

\section{A gestão educacional e a reforma do Ensino Médio}

O conceito clássico de administração, baseado nas contribuições de teóricos como Taylor e Fayol, vem perdendo força nos dias de hoje. Por mais que sua presença ainda seja notável, um novo conceito vem ganhando força e preenchendo as lacunas deixadas pela administração: a gestão. A gestão não se propõe a negar a administração, mas a conduzir novos desdobramentos para a mesma; seria uma espécie de revisão, de reorganização de preceitos básicos. Por mais que para alguns a mudança não seja tão perceptível, autores como Lück (2011) e Hora (2009) trazem-na como a chegada de um novo paradigma, descentralizado, socializado, um antigo jogo com novas regras.

A gestão deve compreender aspectos administrativos e pedagógicos. Pensar nestas instâncias isoladamente, sem a teia que deve tecer um trabalho em equipe é

RPGE - Revista on line de Política e Gestão Educacional, Araraquara, v. 22, n. esp.1, p. 159-176, mar., 2018. 
caminho para um controle autoritário, uma gestão monolítica e autocrática. É preciso, em nome da qualidade que se pretende, enxergar as idiossincrasias do cotidiano e relacioná-las com questões maiores, de interesse coletivo, em nome de um bem maior para os atores do processo educacional.

A redemocratização do país após duas décadas de controle ditatorial fez com que as organizações fossem forçadas a se reorganizarem e os modelos centralizadores perdessem força, dando margem para que a gestão ampliasse o papel da administração. Lück (2011) aponta que a nova concepção de realidade traz uma ótica interativa e dinâmica, ou seja, as organizações precisaram rever o modelo até então adotado, tendo na liderança um elemento central de mudança. Através da liderança, o gestor mobiliza o talento, se afastando do modelo de controle e cobrança. É um modelo descentralizado, em que a responsabilidade é compartilhada e todos são convidados a pensar o processo. Lück (2011, p. 106) aponta que no modelo administrativo "a autoridade do dirigente é centrada e apoiada em seu cargo". Dentro ainda de um modelo fordista, a especialização controlada é característica da administração. Somente o dirigente tem a visão geral para poder supervisionar, cobrar e consertar os erros pontuais. Os aspectos qualitativos prevalecem no modelo da gestão. Ao invés de um foco no quantitativo, como impera no modelo da administração, busca-se a transformação, a qualidade, fazer sempre o melhor, ao invés da simples otimização de recursos.

À gestão cabe então gerir a dinâmica dos processos que ocorrem em uma organização, levando em conta o cenário exterior e interior, buscando descentralizar o poder, compartilhar responsabilidades, dar possibilidades de compreensão do quadro geral a todos os participantes, buscando inovar através da transformação e não da mera importação de modelos. Gerir é promover o debate, a troca de ideias, elevando a organização a um novo patamar. E em tempos de crise das instituições, a liderança do gestor é ainda mais necessária, na medida em que a atmosfera de incerteza pode prejudicar o bom andamento dos processos e o planejamento das ações.

A reforma do Ensino Médio, trazida a público pela Medida Provisória n. 746/2016 e materializada na Lei 13.415 (BRASIL, 2017) fomentou a desconfiança de muitos gestores de instituições públicas e privadas, inicialmente pela falta de compreensão de sua real intenção. Por um lado, acredita-se que a proposta foi formulada na tentativa de o governo de criar uma agenda propositiva, para escamotear os escândalos envolvendo o seu primeiro escalão, inclusive o Presidente da República. O texto traz profundas mudanças no modelo de organização do Ensino Médio, criando 
responsabilidades novas para os sistemas de ensino, sobretudo os estaduais, e para a escolas privadas. A seguir, destacamos alguns pontos importantes dessas mudanças, acrescidas de comentários críticos acerca dos desafios apontados para a gestão:

Art. $24 \S 1^{\circ}$ A carga horária mínima anual de que trata o inciso I do caput deverá ser ampliada de forma progressiva, no ensino médio, para mil e quatrocentas horas, devendo os sistemas de ensino oferecer, no prazo máximo de cinco anos, pelo menos mil horas anuais de carga horária, a partir de 2 de março de 2017 (BRASIL, 2017).

A primeira mudança apontada pelo texto diz respeito à mudança de carga horária para o Ensino Médio. Segundo o texto, deverá haver um aumento progressivo do tempo de permanência do aluno na escola, vislumbrando ao final a carga horária de 7 horas diárias. Esse apontamento tem impactos diferentes entre as escolas públicas e as privadas. Nestas, talvez esse aumento proposto tenha um impacto positivo direto, na medida em que aumentarão os valores de suas mensalidades e poderão, a partir da mudança do artigo 318 da Consolidação das Leis do Trabalho trazida pela lei (BRASIL, 2017) contar com os mesmos profissionais em mais de um turno. Obviamente o aumento das mensalidades fará com que algumas famílias não possam mais arcar com os custos das escolas privadas.

Porém, na escola pública, a realidade é mais complexa. Primeiramente, deixamos claro que a educação integral em tempo integral é algo desejável, algo já encontrado nas escolas de elite. Segundo Najjar, Carneiro e Morgan (2017, p. 64), "a reorganização de tempos e de espaços consiste em um ponto crucial no desenvolvimento de uma instituição escolar que tenha como norte a integralidade do ser humano [...]". Os autores apontam que as escolas privadas, voltadas aos filhos das classes médias e altas, já contam com diversas opções de aulas extras e de jornadas ampliadas, possibilitando aos alunos uma vivência muito mais ampla e significativa no meio escolar. Nas redes públicas, essa realidade é diferente: há projetos que tentaram levar isso a frente, como os Centros Integrados de Educação Pública (CIEPs), nos anos 1980 e 1990 no Rio de Janeiro ou iniciativas novas, como as Escolas do Amanhã, mas o Ensino Médio, em sua esmagadora maioria, funciona em tempo parcial.

Segundo dados do Censo Escolar 2016, somente 6,4\% dos alunos do Ensino Médio estudam em tempo integral ${ }^{6}$. Há redes, inclusive, em que há falta de vagas

6 Disponível em: <http://www.brasil.gov.br/educacao/2017/02/cresce-numero-de-matriculas-no-ensinomedio-integral>. Acesso em: 4 out. 2017.

RPGE - Revista on line de Política e Gestão Educacional, Araraquara, v. 22, n. esp.1, p. 159-176, mar., 2018. 
devido à concentração populacional e a mesma escola funciona em 4 turnos: das $7 \mathrm{~h}$ às $11 \mathrm{~h}$, das $11 \mathrm{~h}$ às $15 \mathrm{~h}$, das $15 \mathrm{~h}$ às $19 \mathrm{~h}$ e das $19 \mathrm{~h}$ às $23 \mathrm{~h}$. Exemplos como esse mostram que os estados não estão preparados para implementarem a jornada integral em todas as suas escolas de Ensino Médio, sem que haja um nova política de financiamento. Ao mesmo tempo que o Governo Federal quer fomentar isso, deixou de lado o Plano Nacional de Educação e cortou pela raiz qualquer possibilidade de realização da Meta 20, que trata do aumento da percentual relacionado ao PIB para educação, no momento em que se aprovou a Emenda Constitucional n. 95, a do teto de gastos, que limita à inflação o aumento do orçamento público pelos próximos 20 anos.

Assim, este primeiro trecho levantado da nova norma jurídica apresenta-se como um problema para os gestores dos sistemas de ensino e também para os escolares, que terão que reorganizar espaços, buscar orçamento para construir mais salas de aula, contratar mais professores, comprar mais merenda escolar, ainda que no final, o saldo possa ser positivo. $\mathrm{O}$ açodamento da medida, sem consulta prévia é seu maior problema, acompanhado do perfil do aluno do Ensino Médio, que muitas vezes trabalha e contribui com a renda familiar e que talvez não tenha interesse ou condições de permanecer na escola durante 7 horas, o que pode agravar o problema da evasão, que é uma constante no Ensino Médio.

O segundo trecho selecionado diz respeito aos currículos:

Art. 35-A. A Base Nacional Comum Curricular definirá direitos e objetivos de aprendizagem do ensino médio, conforme diretrizes do Conselho Nacional de Educação, nas seguintes áreas do conhecimento:

I - linguagens e suas tecnologias;

II - matemática e suas tecnologias;

III - ciências da natureza e suas tecnologias;

IV - ciências humanas e sociais aplicadas. (BRASIL, 2017)

Neste trecho o que chama atenção é a inversão feita pelo Governo no debate das políticas curriculares. De acordo com apontamento feito por Rangel, Mocarzel e Pimenta (2016), as políticas curriculares no Brasil historicamente vêm sendo discutidas em função das políticas avaliativas, quando deveria ocorrer o contrário: primeiro se pensar o currículo, para depois propor o modelo de avaliação que se deseja e que dialoga com as escolhas curriculares. Novamente, vimos este padrão se repetir: trouxeram para a Base Nacional Comum Curricular (BNCC) os quatro descritores 
(incisos I a IV) de área já sacramentados no Enem, de modo que é o exame que está pautando o debate curricular e não o contrário.

Na continuação do Art. 35-A discute-se o que deve compor a BNCC, algo que impacta diretamente a gestão da escola. Neste ponto, é importante lembrar que algumas propostas da Medida Provisória foram modificadas, sobretudo as que tratam do ensino de determinados componentes. Porém, não se reestabeleceu o que se tinha anteriormente, buscou-se uma alternativa minimalista, utilizando a já clássica expressão de Luiz Antônio Cunha.

$\S 2^{\circ}$ A Base Nacional Comum Curricular referente ao ensino médio incluirá obrigatoriamente estudos e práticas de educação física, arte, sociologia e filosofia.

§ 3o O ensino da língua portuguesa e da matemática será obrigatório nos três anos do ensino médio, assegurada às comunidades indígenas, também, a utilização das respectivas línguas maternas.

$\S 4^{\circ}$ Os currículos do ensino médio incluirão, obrigatoriamente, o estudo da língua inglesa e poderão ofertar outras línguas estrangeiras, em caráter optativo, preferencialmente o espanhol, de acordo com a disponibilidade de oferta, locais e horários definidos pelos sistemas de ensino.

§ 5o A carga horária destinada ao cumprimento da Base Nacional Comum Curricular não poderá ser superior a mil e oitocentas horas do total da carga horária do ensino médio, de acordo com a definição dos sistemas de ensino. (BRASIL, 1997)

O parágrafo segundo parece atender a uma demanda social, a partir do descontentamento de uma significativa parcela da população quando da divulgação do texto da MP, que alijava esses componentes do currículo. De fato, os deputados trouxeram de volta a obrigatoriedade da Educação Física, Arte, Sociologia e Filosofia, mas de uma maneira diferente: a lei não as trata como componentes curriculares, ou seja, disciplinas; a lei fala em estudos e práticas. Isso abre espaço para que sejam ensinados apenas conteúdos relativos, mesmo que em outros componentes. Assim, o gestor escolar poderia determinar que se ensine conteúdos de Filosofia dentro das aulas de História, por exemplo, o que bastaria para estar cumprindo a lei. Diferentemente do que ocorre com os componentes do parágrafo segundo, o ensino de Língua Portuguesa e Matemática deverão ser obrigatórios nos três anos do Ensino Médio, algo que já ocorre atualmente nas escolas. Quanto à Língua Inglesa, a mesma também deverá ser obrigatória, ainda que a lei não determine que nos três anos do Ensino Médio, como deve ocorrer no Ensino Fundamental, a partir do que preconiza Artigo 26 (BRASIL,

RPGE - Revista on line de Política e Gestão Educacional, Araraquara, v. 22, n. esp.1, p. 159-176, mar., 2018. 
1996). A oferta da segunda língua é obrigatória, mas é opcional ao aluno cursá-la e recomenda-se que seja a Língua Espanhola, podendo ser outra

Porém, o grande desafio aos gestores dos sistemas e das escolas está no $§ 5^{\circ}$ : a distribuição do tempo entre os componentes e conteúdos obrigatórios da Base Nacional Comum Curricular e todo o aprofundamento em itinerários formativos que se apresentam no Artigo 36. De acordo com a nova redação, a carga horária para oferta do que é estipulado pela BNCC não poderá ser superior a mil e oitocentas horas do total do Ensino Médio. Trata-se, portanto, de um problema matemático para os gestores resolverem. Estamos falando de 600 horas anuais, no máximo, que podem ser dedicadas ao que estabelece a Base. Apesar de não termos ainda o documento publicado, a fim de aferirmos a real incompatibilidade, desconfiamos que a mesma seguirá a estrutura proposta ao Ensino Fundamental, na medida em que se trata, em última instância, de documento público e a própria propaganda do Ministério da Educação, veiculada no rádio e na televisão, afirma que a Base contemplará todos os componentes.

O problema encontra-se precisamente na distribuição das horas: 600 horas anuais dedicadas à BNCC e 800 horas anuais voltadas aos itinerários formativos. Partindo do que estabelecem as Diretrizes Curriculares Nacionais da Educação Básica (2013), são doze os componentes obrigatórios: Língua Portuguesa, Língua Inglesa, Arte, Educação Física, Matemática, Biologia, Química, Física, História, Geografia, Sociologia e Filosofia), com a possibilidade ainda de uma segunda língua estrangeira e de outros componentes, a partir da decisão do sistema de ensino ou da escola. Ao abordarmos a questão dos itinerários, o novo texto da LDB traz a seguinte construção.

Art. 36. O currículo do ensino médio será composto pela Base Nacional Comum Curricular e por itinerários formativos, que deverão ser organizados por meio da oferta de diferentes arranjos curriculares, conforme a relevância para o contexto local e a possibilidade dos sistemas de ensino, a saber:

I - linguagens e suas tecnologias;

II - matemática e suas tecnologias;

III - ciências da natureza e suas tecnologias;

IV - ciências humanas e sociais aplicadas;

V - formação técnica e profissional. (BRASIL, 2017)

Ora, caberia então ao gestor, juntamente com sua equipe pedagógica, pensar em uma distribuição viável para a carga horária do Ensino Médio. Porém, essa viabilidade é cada vez mais complexa, na medida em que racionalmente, é difícil imaginar que oito ou dez componentes podem ser lecionados em 600 horas anuais. Tomemos como 
exemplo o cenário abaixo, de uma escola que opte por ofertar apenas um itinerário formativo: Matemática e suas tecnologias. Dentro deste itinerário, poderíamos incluir outros componentes que possuem sinergia, como Física e Química, de modo a constituir um corpus de estudos e práticas que façam uso da Matemática em distintos contextos e com aplicação diversificada e concreta. Sendo assim, a distribuição seria a seguinte, em dois cenários:

Tabela 1: Ensino Médio com 1000 horas (5 horas diárias)

\begin{tabular}{|c|c|c|}
\hline Carga Horária Total & BNCC & Itinerário Formativo \\
\hline $\begin{array}{l}1000 \text { horas } \\
5 \text { horas diárias }\end{array}$ & $\begin{array}{c}600 \text { horas } \\
3 \text { horas diárias }\end{array}$ & $\begin{array}{c}400 \text { horas } \\
2 \text { horas diárias }\end{array}$ \\
\hline & 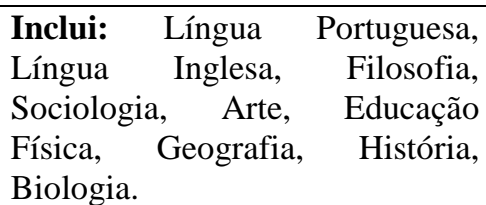 & Inclui: Matemática, Química, Física. \\
\hline
\end{tabular}

Fonte: Elaborado pelos autores

Tabela 2: Ensino Médio com 1400 horas (7 horas diárias)

\begin{tabular}{|c|l|c|}
\hline Carga Horária Total & \multicolumn{1}{|c|}{ BNCC } & \multicolumn{1}{|c|}{ Itinerário Formativo } \\
\hline $\begin{array}{c}\text { 1400 horas } \\
7 \text { horas diárias }\end{array}$ & \multicolumn{1}{|c|}{800 horas diárias } \\
& $\begin{array}{l}\text { Inclui: Língua Portuguesa, } \\
\text { Língua Inglesa, Filosofia, } \\
\text { Sociologia, Arte, Educação diárias }\end{array}$ & Inclui: Matemática, Química, Física. \\
& $\begin{array}{l}\text { Física, Geografia, História, } \\
\text { Biologia. }\end{array}$ & \\
\hline
\end{tabular}

Fonte: Elaborado pelos autores

O problema que se apresenta à gestão dos tempos escolares aos gestores se dá especificamente no que tange à oferta da BNCC. Como será possível ofertar nove ou dez componentes em 1800 horas, nos três anos do Ensino Médio, ainda que não haja obrigatoriedade de se ofertar todos nos três anos? Em termos de distribuição real, estamos falando aproximadamente em 3 aulas diárias, ou seja, 15 ou 16 aulas semanais que deverão ser distribuídas entre tantos componentes. Um aluno do "novo" Ensino Médio, cujo itinerário formativo seja o do exemplo, Matemática e suas tecnologias, poderá ter, no máximo, duas aulas semanais de cada componente, talvez três.

\section{Considerações Finais}

RPGE - Revista on line de Política e Gestão Educacional, Araraquara, v. 22, n. esp.1, p. 159-176, mar., 2018. 
Por entendermos que qualidade e quantidade são aspectos indissociáveis (MOCARZEL, 2013; DEMO, 2009), questionamos: é possível ensinar Língua Portuguesa com qualidade com apenas duas ou três aulas semanais em todo o Ensino Médio? O aluno terá condições de dominar competências básicas para a sua formação humana e profissional e mais pragmaticamente, para ter êxito em exames de acesso à Educação Superior, uma vez que a leitura e a escrita são duas das competências mais valorizadas, mesmo para postulantes a cursos da área exata? Como os gestores privilegiarão os componentes da $\mathrm{BNCC}$ na distribuição da carga horária? Ainda que estejamos falando de estudos e práticas de quatro componentes - Arte, Educação Física, Sociologia e Filosofia - haverá carga horária suficiente para todos os conteúdos propostos?

Os questionamentos levantados colocam os gestores em uma situação complexa: os mesmos perdem autonomia para a inclusão de novos componentes, alguns deles que poderiam responder a demandas da própria comunidade escolar. Também, passam a gerir seus professores a partir da otimização de recursos humanos, encerrando vagas de trabalho para os componentes que reduzirem carga horaria e concentrando naqueles de maior intensidade. Por fim, a própria ideia do itinerário formativo, que a princípio é interessante, fica prejudicada, pois a falta de recursos humanos deverá fazer com que a grande maioria das escolas opte pelas Linguagens ou Ciências Humanas e Sociais Aplicadas, o que prejudica o desenvolvimento da Matemática e das Ciências Naturais, pontos fracos em nosso país. Uma saída possível para os gestores será recorrer ao $\S 3^{\circ}$ do Artigo 36, que tem a seguinte redação:

$\S 3^{\circ}$. A critério dos sistemas de ensino, poderá ser composto itinerário formativo integrado, que se traduz na composição de componentes curriculares da Base Nacional Comum Curricular - BNCC e dos itinerários formativos, considerando os incisos $\mathrm{I}$ a $\mathrm{V}$ do caput. (BRASIL, 2017)

A partir dessa possibilidade, muitas escolas irão conjugar itinerários, como uma maneira de gerir a carga horária da escola com um pouco mais de flexibilidade, podendo preparar os alunos com mais tempo e profundidade. Assim, a própria ideia fundante da reforma do Ensino Médio se perde, na medida em que volta-se a ter o modelo que hoje é comum, sobretudo em escolas privadas: turmas separadas a partir de áreas de interesse. A limitação de recursos impossibilitará que escolas ofertem três ou quatro itinerários, na medida em que necessita-se de mais professores, mais salas de 
aula e diminui-se a razão professor/aluno, ponto chave do custeio de uma instituição escolar.

Portanto, enxergamos a reforma do Ensino Médio como uma proposição sem condições de operacionalização pela grande maioria dos gestores escolares públicos e privados, que precisariam de mais recursos, algo hoje impensável, sobretudo em tempos de crise e de corte de direitos. Trata-se de uma política que permanecerá no contexto de influência, mas terá grandes dificuldades de completar o ciclo até o contexto da prática, uma vez que as escolas e os sistemas buscarão, na concepção de Ball, Maguire e Barun (2016), formas de atuação, tradução e reinterpretação da política.

\section{REFERÊNCIAS}

ALTMANN, Helena. Influências do Banco Mundial no projeto educacional brasileiro. Educação e Pesquisa, v. 28, n. 1, p. 77-89, 2002.

BALL, Stephen. Profissionalismo, gerencialismo e performatividade. Cadernos de Pesquisa, São Paulo, v. 35, n. 126, set./dez., 2005.

BALL, Stephen; BOWE, Richard. Subject departments and the 'implementation'of National Curriculum policy: an overview of the issues. Journal of Curriculum Studies, v. 24, n. 2, p. 97-115, 1992.

BALL, Stephen; MAGUIRE, Meg; BRAUN, Annette. Como as escolas fazem as políticas: atuação em escolas secundárias. Ponta Grossa, PR: Editora UEPG, 2016.

BALL, Stephen; MAINARDES, Jefferson (Orgs.). Políticas educacionais: questões e dilemas. São Paulo: Cortez, 2011.

BRASIL. Ministério da Educação. Secretaria de Educação Básica. Secretaria de Educação Continuada, Alfabetização, Diversidade e Inclusão. Conselho Nacional da Educação. Diretrizes Curriculares Nacionais Gerais da Educação Básica. Brasília: MEC, SEB, DICEI, 2013. Disponível em: <http://portal.mec.gov.br/docman/julho2013-pdf/13677-diretrizes-educacao-basica-2013-pdf/file>. Acesso em: 10 set. 2017.

BRASIL. Diretrizes e Bases da Educação Nacional. Lei no 9.394/1996, de 20 de dezembro de 1996. Brasília, DF: Senado Federal, 1996. Disponível em: <http://www.planalto.gov.br/ccivil_03/leis/L9394.htm>. Acesso em: 29 mar. 2018.

BRASIL. Lei 13.415, de 16 de fevereiro de 2017. Brasília, DF: Câmara dos Deputados, 2017. Disponível em: <http://www.planalto.gov.br/ccivil_03/_ato20152018/2017/lei/L13415.htm>. Acesso em: 29 mar. 2018.

BRASIL. Ministério da Administração Federal e Reforma do Estado. Plano diretor da reforma do aparelho do Estado. Brasília: Presidência da República, Câmara da Reforma do Estado, 1995. Disponível em:

RPGE - Revista on line de Política e Gestão Educacional, Araraquara, v. 22, n. esp.1, p. 159-176, mar., 2018. 
<http://www.bresserpereira.org.br/Documents/MARE/PlanoDiretor/planodiretor.pdf $>$. Acesso em: 29 mar. 2018.

CUNHA, Luiz Antônio. Crise e reforma do sistema universitário (debate). Novos Estudos, São Paulo, CEBRAP, n. 46, nov. 1996.

DEMO, Pedro. Educação e qualidade. Campinas, SP: Papirus, 2009.

HORA, Dinair L. da. Gestão democrática na escola: artes e ofícios da participação coletiva. Campinnas, SP. Papirus, 2009.

HYPOLITO, Álvaro Moreira. Políticas curriculares, Estado e regulação. Educ. Soc., Campinas, v. 31, n. 113, out./dez., 2010.

LÜCK, Heloísa. Gestão educacional: uma questão paradigmática. Petrópolis, RJ: Vozes, 2011.

MAINARDES, Jefferson. Abordagem do ciclo de políticas: uma contribuição para a análise de políticas educacionais. Educ. Soc, v. 27, n. 94, p. 47-69, 2006.

MOCARZEL, Marcelo Siqueira Maia Vinagre. Os caminhos da qualidade na educação: análise do discurso de gestores escolares. Dissertação de Mestrado (Educação). Niterói, RJ: Universidade Federal Fluminense, 2013.

MORGAN, Karine Vichiett.; NAJJAR, Jorge Nassim Vieira.; CARNEIRO, Waldeck Educação integral em São João de Meriti: conceitos em desalinho. Conhecimento \& Diversidade, v. 9, n. 17, p. 61-71, 2017.

OLIVEIRA, Dalila Andrade. A reestruturação do trabalho docente: precarização e flexibilização. Educ. Soc., v. 25, n. 89, 2004.

OZGA, Jenny. Investigação sobre políticas educacionais: terreno de contestação. Porto, Portugal: Porto Editora, 2001.

RANGEL, Mary.; MOCARZEL, Marcelo Maia Vinagre.; PIMENTA, Maria de Fátima Barros. A trajetória das competências e habilidades em educação no Brasil: das avaliações em larga escala para as salas de aula. Revista Meta: Avaliação, v. 8, n. 22, p. 29-47, 2016.

SANTOS, Pablo Silva Machado Bispo dos. Sobre o conceito de Refração Política: mais uma chave dos segredos das Ciências Humanas. Revista Espaço Acadêmico, v. 12, n. 137, p. 65-73, 2012.

SAVIANI, Demerval. A nova lei da educação: trajetórias, limites e perspectivas. Campinas: Autores Associados, 2008.

SOUZA, Sandra Zákia Lian de; OLIVEIRA, Romualdo Portela de. Políticas de avaliação da educação e quase mercado no Brasil. Educ. Soc., v. 24, n. 84, p. 873-894, 2003. 
VIEIRA, Sofia Lerche. Política educacional em tempos de transição (1985 - 1995). Brasília: Liber Livro, 2008.

\section{Como referenciar este artigo}

MOCARZEL, Marcelo Maia Vinagre; ROJAS, Angelina Accetta; PIMENTA, Maria de Fátima Barros. A reforma do Ensino Médio: novos desafios para a gestão escolar. Revista on line de Política e Gestão Educacional, Araraquara, v. 22, n. esp.1, p. 159176, mar., 2018. E-ISSN:1519-9029.

Submetido em: 04/10/2017

Aprovado em: 14/12/2017 